\title{
Creating boundaries and stops in German: An analysis in Universal Boundary Theory
}

\author{
Samuel Andersson*
}

\begin{abstract}
This paper discusses the nature of prosodic representations, focusing on a case study from the phonology of Standard High German. This language displays devoicing, previously argued to be sensitive to syllables, and glottal stop epenthesis, previously argued to be sensitive to feet. This seems to require at least two prosodic constituents, the syllable and the foot. However, I show that the data can be analyzed straightforwardly in Universal Boundary Theory (UBT), a non-hierarchical theory of prosodic representations using only a single boundary symbol $\mid$. I introduce the central assumptions of UBT, and show that the theory can handle the syllable- and foot-level phonology of German, including affix-specific behavior and phase-based interactions between the syntax and phonology. I argue that UBT provides a better account of devoicing than a class of earlier analyses based on syllables. Moving beyond German, UBT predicts the existence of a new prosodic universal which cannot be captured by a traditional prosodic hierarchy: phonological processes apply top-down, from larger to smaller prosodic units. Future typological work will shed light on the crosslinguistic validity of this prediction.
\end{abstract}

Keywords. phonology; prosody; German; hierarchy; syllable; foot; devoicing; epenthesis; sonority; syntax-phonology interface; exceptionality

1. Introduction. Prosodic representations are often taken to be hierarchically organized into units like moras, syllables, feet, words, and phrases (Selkirk 1981, Nespor and Vogel 1986). Adding this level of representational complexity remedied problems with earlier approaches, where prosodic processes often made reference to complex disjunctions of environments, and a wealth of different boundary symbols (Chomsky and Halle 1968). There is no doubt that this represented progress in our understanding of prosodic phonology. However, in the decades since the introduction of the prosodic hierarchy, many of the phenomena previously thought to require hierarchical representations have been reanalyzed in 'flatter' representational theories. This includes phonotactics (Steriade 1999, Heinz 2007), stress (Scheer and Szigetvári 2005, Faust and Ulfsbjorninn 2018), and vowel harmony (Mailhot and Reiss 2007, Samuels 2009). Against the background of such work, we might ask how much of the complexity of prosodic data can be handled by representationally simpler theories. In this paper, I address this question with a case study from German, where the processes of glottal stop insertion and devoicing seem to require at least syllables and feet. However, I show that Universal Boundary Theory (UBT), which uses only a single boundary symbol |, successfully accounts for these aspects of German prosody. Not only are the core cases handled, but UBT can also account for syntax-phonology interactions, affix-specific behavior, and subtleties in the exact environment for final devoicing. All of this is done while avoiding the problems with earlier boundary-based theories: there is no proliferation of complex representational devices like multiple boundaries or angle brackets, and the rules are formally simple without disjunctions over multiple environments. Since UBT accounts for complexities of the German case, one might wonder whether representations of prosody across

\footnotetext{
* Thanks to audiences at the Annual Meeting on Phonology 2019, and members of the Yale Phonology Reading Group for feedback on versions of this project. All errors are my own. Author: Samuel Andersson, Yale University (samuel.andersson@yale.edu).
} 
languages can be simplified by removing hierarchical representations. This question cannot be addressed using only German data. However, I also identify a new prosodic universal which is predicted by UBT but not by other representational theories. I show that in UBT, it is predicted that phonological processes apply first to larger prosodic units, and only later work their way down to the lower end of the prosodic hierarchy. Considering relevant typological data will allow us to evaluate directly the predictive differences between UBT and hierarchical approaches to prosody.

The remainder of this paper is structured as follows. Section 2 introduces representative data from Standard High German on voicing alternations and glottal stops. Previous analyses are also discussed here. Section 3 introduces the central assumptions of Universal Boundary Theory, as well as assumptions which are made in this paper but which do not form a central part of the theory. Section 4 applies the UBT analysis to the German data, showing how it is accounted for in a theory without hierarchical representations. Section 5 provides discussion, and identifies further predictions made by UBT. Section 6 concludes.

2. Data. This section introduces the data from Standard High German which will be analyzed in the rest of the paper. We begin by considering alternations between voiced and voiceless obstruents, and then move on to the distribution of the glottal stop. Note that there is significant interspeaker variation in these phenomena across German dialects. I do not attempt to analyze all varieties belonging to the E-language German, but instead focus on those I-languages which are often categorized as Standard High German, and which are referred to simply as 'German' throughout. References for each data point are provided, and interested readers are encouraged to consult these for further discussion of cross-dialect variation.

2.1. VoICING ALTERNATIONS. German is well-known for distributional restrictions on the two laryngeal series in the language. The 'voiceless' series, which is realized with long-lag positive VOT, occurs in all environments. But the 'voiced' obstruents, which are often plain voiceless phonetically, do not occur word-finally or before other obstruents (for the phonetics, see Wagner 2002). The data below exemplify these distributional restrictions with non-alternating voiceless stops, as well as stops which alternate between voiced and voiceless. Throughout, data is in a broad IPA transcription with an acute accent marking primary stress, and secondary stress unmarked. Abbreviations follow the Leipzig Glossing Rules.
a. i. [búnt] 'colorful (PRED)'
ii. [búnt-ə] 'colorful (ATTRIBUTIVE $\square$ )'
(Wiese 1996: 201)
b. i. [bớnt] 'union (NOM)'
ii. [bứnd-ə] 'union (DAT, archaic)'
(Wiese 1996: 201)
c. i. [lé:z-ən] 'to read'
ii. [lé:s-ba:e] 'readable'
(Itô and Mester 2003: 273)

(1) a. and b. show a minimal pair for voicing in the suffixed forms, even though both words have a voiceless stop in the unsuffixed form. (1) c. shows that there are also alternations wordmedially. There is a longstanding debate about whether words like 'colorful' and 'union' are really homophonous in their unsuffixed forms. A recent meta-analysis of fourteen studies found that there are small but significant phonetic differences in the preceding vowel (Nicenboim et al. 2018). I retain the traditional transcriptions here, but acknowledge that these differences are real. 
The examples in (2) below illustrate an important but often-ignored aspect of voicing alternations in German: within morphemes, voicing is contrastive before sonorants (see Wagner 2002, Féry 2004, Hall 2005, Iverson and Salmons 2007, Brockhaus 2012).
a. i. [mágma] 'magma'
ii. [Pákmə] 'acme'
(Wagner 2002: 382)
b. i. [Pá:dle] 'eagle'
ii. [Pátlas] 'atlas'

(Wagner 2002: 382)

2.2. ThE GLOTTAL STOP. The distribution of the glottal stop in German is generally predictable (Wiese 1996: 58). In the varieties of interest to us, the distribution of its presence and absence is as in (3).
a. i. [Pá:təm] 'breath'
ii. [Pató:m] 'atom'
(Wiese 1996: 59)
b. i. [ká:os] 'chaos'
ii. [ka:Pó:t-I]] 'chaotic'
(Szczepaniak 2014: 174)
c. [Páp-Pebən] 'to ebb away'
(Szczepaniak 2014: 174)
d. i. [Jtu:dént-Pin] 'student (any gender)'
ii. [Jtu:dént-In] 'student (female)'
(see Banovics 2012, Stratton 2018, Zinfoun 2018, Kolek forthc.)

Glottal stops are found word-initially, as in (3) a., before a stressed vowel in hiatus, as in (3) b., between prefixes and their roots, as in (3) c., and with a small set of suffixes, as in (3) d. For other suffxal contrasts in the presence of glottal stop, see Alber (2001) and Booij (1985).

2.3. PREVIOUS ANALYSES. Previous work has often analyzed the voicing alternations above in terms of syllables, with devoicing applying in the coda or in absolute syllable-final position. For examples of syllable-based devoicing analyses for German, see Vennemann 1972, Kloeke 1982: 128-134, Wiese 1996: 200-206, Itô and Mester 2003, among many others). Such analyses need to say something about the mismatch between the syllabifications required to account for devoicing, and the syllabifications provided by native speakers. For example, German speakers do not judge [gm] to be a possible onset (see Wagner 2002: 382, Féry 2004: 67, fn. 4), and yet, as illustrated in (2), such clusters show onset-like behavior in that the [g] does not devoice. This is not to say that this is an unsolvable problem, and there are two main analytical options. The first is to maintain that devoicing is sensitive to syllables, but that there are other factors which can cause coda obstruents to remain voiced in some circumstances (e.g. Hall 2005 on paradigm uniformity, although this cannot account for the monomorphemic cases in (2)). The second approach (e.g. Vennemann 1972) insists on syllabifications such as [ma.gma], so that the layperson's concept of a syllable is not exactly identical to the formal phonological construct which happens to bear the same name.

Although Universal Boundary Theory lacks a notion of syllable, a version of the second option will be pursued in this paper. Of course, something must now be said about the native speaker judgments. A likely explanation is that native speakers are reluctant to produce [ma] and 
[gma] as syllables in isolation: monosyllabic words do not end in [a] in German (Hall 1999: 106), and [gm] does not occur word-initially (Wagner 2002: 382). Speaker judgments may thus be affected by what is phonotactically possible at word edges (see Treiman and Danis 1988, and Samuels 2009: 106-7 for discussion of experimental results from English).

The distribution of the glottal stop in German has often been analyzed in terms of feet. The basic analysis is that if the first syllable of a foot is vowel-initial, a glottal stop is inserted (Wiese 1996: 58-61; see also Hall 1992, Yu 1992, Féry 1995). Such an account is appealing since glottal stop insertion is partly conditioned by stress. A glottal stop is inserted between two vowels only if the second vowel is stressed, with the stress plausibly indicating the presence of a foot boundary (see Féry 1995 for this argument). Of course a foot-based account requires particular assumptions about footing, notably in word-initial position and with the prefixes that trigger glottal stop insertion. A particular challenge seems to be suffixes which contrast for the presence or absence of glottal stop, as shown in (3) above. It could be assumed that the suffixes with glottal stops are underlyingly footed, but I am not aware of any work which makes its assumptions about such cases explicit. In section 4, we will see that a simple rule for glottal stop insertion in Universal Boundary Theory, together with explicit derivations of all of the required boundaries.

3. Introduction to Universal Boundary Theory. Universal Boundary Theory (UBT) is a theory of prosodic representations, which will be used in the analyses later in this paper. This section introduces the conceptual and empirical motivations for UBT, and lays out the additional assumptions, not strictly part of UBT, which I will make use of in following sections.

In the history of phonology, analyses with various boundary symbols have been proposed. Chomsky and Halle (1968) had many boundary types for different morphological domains, as seen in the underlying form /æd=vIs\#or+y/ 'advisory' (Chomsky and Halle 1968: 134). Syllable boundaries, often written $\$$, were re-introduced into generative phonology in the 1970 s (Goldsmith 2011). However, the relevance of boundary symbols has decreased sharply with the popularization of various hierarchical representations of prosodic structure, as in Metrical phonology (Liberman 1975), and the familiar prosodic hierarchy (Selkirk 1981, Nespor and Vogel 1986). An exception is grid-based theories of stress often use ( and ) boundaries for feet (Halle and Vergnaud 1987, Hayes 1995, Idsardi 2009). Reiss (2009) uses only a single, nondirectional foot boundary marked by $\mid$.

One may wonder, then, why anyone today would adopt a boundary-based theory over commonly-used hierarchical alternatives. One argument is conceptual, and states simply that we should use as few representational primitives as possible, due to Occam's Razor. If we can avoid hierarchical representations of prosody, there is no need to add this representational complexity to the theory, the argument goes. For work which applies this line of thinking to prosody, see Reiss (2009) and Samuels (2009). Another line of argument is more empirical: flat (non-hierarchical) approaches to prosodic phenomena have been successful in many of the domains where hierarchies were previously thought to be essential. This includes flat models of phonotactics (Steriade 1999, Heinz 2007), stress (Scheer and Szigetvári 2005, Faust and Ulfsbjorninn 2018), and vowel harmony (Mailhot and Reiss 2007, Samuels 2009), to mention a few examples. If these phenomena can be handled without hierarchical prosodic representations, exploring a non-hierarchical approach like Universal Boundary Theory seems to be well worth our time. Of course, the ultimate test for any theory lies in what predictions it makes. In section 5, I discuss a new typological prediction made by Universal Boundary Theory, and describe how to go about testing it on crosslinguistic data.

At its core, UBT proposes the existence of a boundary symbol, which I write $\mid$ and read 
simply as 'boundary'. Boundaries are formally represented as the feature bundle [-segment], and are part of the segmental string in exactly the same way as any other segmental material. The division between the segmental and the prosodic is thus intentionally blurred, something which we will use to our advantage in the analysis of glottal stop insertion in section 4 . One difference is that unlike other features, [segment] has no phonetic correlates, meaning that like most prosodic structure, the boundary symbol affects the pronunciation of surrounding material but is itself silent. This absence of phonetic correlates is advantageous in that it makes UBT modalityindependent, and in Andersson (2019) I used boundary symbols to account for similar phonological behavior in Italian and ASL. Within individual languages, boundaries may appear in different places and at different times in the derivation, and are generally language-specific. However, the placement of some boundaries is universal; specifically, UBT assumes that inputs to the phonology are automatically padded with an initial and final boundary symbol.

Although UBT is a flat theory of prosody which does not involve hierarchical structure, this does not necessarily mean that all of phonology is flat. It is possible that there is hierarchical structure below the level of the segment, for example, as represented in feature geometry (Clements 1985). There can also be apparent hierarchies in higher prosodic structure, due to the interface with (hierarchical) syntax. In this paper, I assume derivation by phase, where each syntactic phase is spelled out separately by the phonology (Seidl 2001, Scheer 2008, Samuels 2009, 2010, Sande and Jenks 2018, Miller 2019, Newell 2019, among others). This will allow us to derive some of the patterns shown by morphologically-complex forms in German, but it is not a core part of UBT, which is in principle compatible with any theory of the syntax-phonology interface. Since the theory itself is so minimalist, it must be paired with additional assumptions to make it possible to analyze data using UBT. Another such assumption that I will make in this paper is that phonological computation works by extrinsically-ordered rewrite rules of the form $\mathrm{A} \rightarrow \mathrm{B} / \mathrm{C}$ _D. This will straightforwardly handle some of the complex derivations required for German, but I stress that since UBT is a theory of representations, it is compatible with any theory of computation.

We have now seen the core aspects of Universal Boundary Theory. It represents prosody with a boundary symbol, formally [-segment], which is part of the segmental string, and which has no phonetic realization. Boundaries are universally added as delimiters at the start and end of inputs to the phonology. Beside these central assumptions of the theory, this paper also relies on phonological rules, and derivation by phase, to analyze particular patterns in the phonology of German. In the next section we begin to carry out this analysis.

4. Analysis. This section will present a Universal Boundary Theory analysis of the German data from section 2. We will see that both devoicing and glottal stop insertion are sensitive to the presence of a boundary symbol. Despite this, there is a straightforward analysis where a single boundary suffices to account for both processes. I will begin by analyzing glottal stop insertion, followed by devoicing, and then combine the two analyses into a single rule-based grammar.

4.1. GLOTTAL STOP INSERTION. Let's begin by providing the rules which will guarantee glottal stop insertion in the right places. I will assume the following rule:

(4) Glottal Stop Insertion (GSI)

$\emptyset \rightarrow$ ? / I_ V

In other words, we insert a glottal stop between a boundary and a vowel. For this to work, we now have to make sure that there are boundaries in all of the right places. Recall from section 2 that glottal stops appear word-initially, in hiatus, between prefixes and stems, and in an unpre- 
dictable set of suffixes. Given the assumptions made in section 3, the word-initial behavior comes for free. Whenever a word is used as the input to phonological computation, it is automatically padded with an initial and final boundary. A word like /ató:m/ 'atom' will then become |ató:m|. Since the word now begins with a boundary and a vowel, the glottal stop insertion rule will apply and produce the correct surface form [|Pató:m|] 'atom'.

Boundaries also come for free in the prefix-stem cases, given the assumptions I have made about the syntax-phonology interface. Biskup et al. (2015) argue that in complex verbs in German, prefixes and their stems are separated by a phase boundary. Spellout by phase gives the phonology its inputs one phase at a time, and so a verb like abebben 'to ebb away' is first |ćbən| (phase 1, automatic initial and final boundaries) and then |áb|cbən| (phase 2, new automatic boundaries). Glottal stop insertion then correctly produces both glottal stops between boundaries and vowels: |Páb|?zbən| (for the devoicing of the /b/ in the prefix, see 4.2).

For hiatus cases, like [ka:?ó:t-If] 'chaotic', the glottal stop, and the boundary that guarantees its insertion, is morpheme-internal. Since /ka:/ and /o:t-I $\mathrm{J} /$ are not in separate phases, this cannot be an automatic boundary in the sense above. However, glottal stops are predictable in this hiatus environment, and so we can write a simple phonological rule to insert boundaries in the right places:

(5) Boundary Insertion (BI) $\emptyset \rightarrow \mid / \mathrm{V}_{-} \mathrm{V}^{1}$

This turns |ka:ó:t-If| into |ka:|ó:t-If|, with the requisite boundary-vowel configuration. A glottal stop is inserted by (4), which must follow (5), producing the correct [|ka:|Pó:t-If|].

The only remaining glottal stops that need to be accounted for now are those that occur with an idiosyncratic set of suffixes. In theory, one could imagine a syntactic account here, but I am not aware of any motivation for thinking that the suffixes [-In] 'feminine' and [-?In] 'any gender' involve different phase boundaries. Both suffixes are identical except for which genders they index, so I assume that this difference is not phase-related. Instead, I propose that suffixes which do trigger glottal stop insertion contain a boundary symbol underlyingly: /In/ 'feminine' vs /|in/ 'any gender'. This type of solution is not available in all theories. Many people hold that prosodic structure cannot be stored in the lexicon (for discussion, see Blevins 1995, Goldsmith 2011, Vaux and Samuels 2018 among others). However, UBT does not have any segmentalprosodic divide, and the representations of segments and the boundary symbol are formally the same entity, namely a feature bundle. [segment] should therefore be able to function contrastively within languages, just like [voice] or [nasal]. In German suffixes we see a case where this analytical possibility is advantageous, allowing us to capture the affix-specific behavior of glottal stop insertion. For other examples of contrastive ///, see Andersson (2019)'s analyses of Italian and ASL. With this background, we have all of the boundaries we need to correctly insert glottal stops. Full derivations of all glottal stop types are provided below, where each rule is referred to by an abbreviation as well as the numbered example where it was introduced:

\footnotetext{
${ }^{1}$ I assume that stress is present at this stage of the derivation, and possibly even underlyingly: [té:no: $\left.\mathrm{e}\right]$ 'substance' vs [te:nó:e] 'tenor' (Wiese 2000: 9).V́ refers to the feature bundle [+syllabic, +stress]; for evidence that stress can be a phonological feature, see Andersson (2020) on why this is required in Abkhaz.
} 
(6) Derivations for glottal stops

\begin{tabular}{|c|c|c|c|c|}
\hline Phase 1 & |ató:m| & |ka:ó:tıf| & |ćbən| & |ftu:dént|In| \\
\hline Phase 2 & ------- & ---------- & |áb|cbən| & ------ \\
\hline $\mathrm{BI}(5)$ & -------- & |ka:|ó:tIf| & ------- & ------------- \\
\hline GSI (4) & |Pató:m| & |ka:|Pó:tıf| & |Páb|Pzbən| & |ftu:dént|?in| \\
\hline Other (see 4.2) & ------- & --------- & |Páp|Pzbən| & ----------- \\
\hline Output & |Pató:m| & |ka:|?ó:tif| & |Páp|Pzbən| & |ftu:dént|PIn| \\
\hline Translation & 'atom' & 'chaotic' & 'to ebb away' & 'student (any gender)' \\
\hline
\end{tabular}

4.2. Devoicing. Our next task is to find a set of rules for devoicing. Again we will start out with the boundary-sensitive devoicing rule, and then make sure that we have boundaries in all of the right places for the rule to apply. I propose the following devoicing rule for German:

(7) Devoicing (DV)

[+voice, -sonorant] $\rightarrow[$-voice $] / \_\mid$

This rule applies devoicing to any obstruent before a boundary. Since devoicing is sensitive to the sonority in consonant clusters, we now need to place sonority-sensitive boundaries. Note that word-final devoicing comes for free because of automatic initial and final boundaries: /bond/ becomes |bond|, and we now have an obstruent before a boundary, with devoicing giving |bont| as desired. I will use two boundary-inserting rules, one for obstruent-sonorant clusters, and another for all other clusters.

$$
\begin{array}{ll}
\text { a. } & \text { Sonority-Increasing Clusters (SIC) } \\
& \varnothing \rightarrow \mid / V_{-}[\text {-sonorant }][\text {-syllabic, +sonorant }] \\
\text { b. } & \text { Other Clusters (OC) } \\
& \varnothing \rightarrow \mid / \text { VC_C }
\end{array}
$$

The first rule applies to a form like |mágma| 'magma' to give |má|gma|, since $\mathrm{g}$ is an obstruent and $\mathrm{m}$ a sonorant. The second rule does not change this form, since the string |má|gma| does not contain a VCC sequence (it does contain V|CC). In a form like |lé:zba: $\bullet$ | 'readable', the zb cluster is obstruent-obstruent, and the first rule does not apply. The second rule does apply, since é:zb is a VCC sequence. We then get |lé:z|ba:e|, and the $\mathrm{z}$ before a boundary devoices by (7), giving the correct output |lé:s|ba:e|. Using the rules above, and applying them in exactly the order shown below, we correctly account for the devoicing data as shown in the following derivations:

(9) Derivations for devoicing

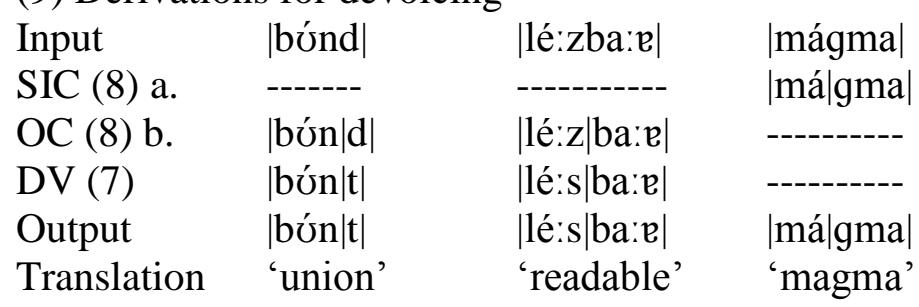

4.3. PutTing EVERYTHING TOGETHER. Having seen analyses for devoicing and glottal stop insertion, it is time to combine them into a single grammar. As noted in the beginning of this section, this is a non-trivial challenge, since we have two different processes applying in different environments, but which are both sensitive to the presence of the same boundary symbol. However, with the rules from the preceding subsections, it is as simple as applying the glottal stop rules before the devoicing rules. The derivation table below shows that we derive the correct outputs, 
with voiceless obstruents and glottal stops in all and only the right places, for all of the data we have seen:

(10) Derivations for glottal stops and devoicing

\begin{tabular}{|c|c|c|c|c|c|}
\hline Phase 1 & |ató:m| & |bónd| |mágma| & |ka:ó:tıj| & |ćbən| & |ftu:dént|in| \\
\hline Phase 2 & ------- & ------- --------- & ---------- & áb|cbən| & \\
\hline $\mathrm{BI}(5)$ & -------- & ------- ---------- & |ka:|ó:trf| & ------ & ------ \\
\hline GSI (4) & |Pató:m| & -------- ----------- & |ka:|Pó:tıf| & |Páb|Pعbən| & |ftu:dént|?In| \\
\hline SIC (8) a. & -------- & ------- |má|gma| & ---------- & ------ & ------------ \\
\hline OC (8) b. & -------- & |bún|d| --------- & ---------- & & $\left|\int t u: d \varepsilon ́ n\right| t|P i n|$ \\
\hline DV (7) & -------- & $\mid$ bún $|t|$ & ---------- & |Ráp|?zbən| & ----------- \\
\hline Output & |Pató:m| & |bớn|t| |má|gma| & |ka:|Pó:tıf| & |Páp|?cbən| & $\left|\int t u: d \varepsilon ́ n\right| t \mid$ PIn| \\
\hline Translation & 'atom' & 'union' 'magma' & 'chaotic' & 'to ebb away' & $\begin{array}{l}\text { 'student } \\
\text { (any gender)' }\end{array}$ \\
\hline
\end{tabular}

5. Discussion and consequences. It is of course a welcome result that our analysis in the previous section correctly derives all of the data. But why exactly does a single boundary symbol suffice for two processes applying in different environments? How come the boundaries used for glottal stop insertion do not get in the way of the boundaries used for devoicing? This section provides an answer, and discusses the conditions under which boundary symbols can co-exist in the same grammar without interfering with other boundary symbols. We will see that understanding how this works leads to a new typological prediction about prosodic phonology: phonological processes should apply top-down, from larger to smaller prosodic units. As far as I know, this prediction is unique to UBT, and is not made by any other theory of prosodic representations. UBT can therefore be straightforwardly confirmed or falsified in future work by testing if this holds crosslinguistically.

The reason we were able to get away with only a single boundary in the German case has to do with supserset-subset relationships between prosodic edges, which follow from the Strict Layer Hypothesis (Selkirk 1981, 1984, Nespor and Vogel 1986). There is a one-way implicational relationship where every foot edge is also a syllable edge, but it is not the case that every syllable edge is also a foot edge. This implicational relationship holds across prosodic categories generally: between syllables and sub-syllabic constituents, between phrases and words, and so on. There are multiple smaller units making up a larger one, but the edges of the larger unit are aligned with the edges of (one of) the smaller units.

Phrasing the above in a way relevant to German, we can say that the set of syllable edges is a strict superset of the set of foot edges. We can use this to our advantage to avoid boundaries interfering with each other. Since all foot edges are also syllable edges, all glottal stop epenthesis sites will also be devoicing sites. Our strategy is therefore to begin with the boundaries that correspond to foot edges, placing all of these rules earlier in the derivation. Once these boundaries are placed, we insert glottal stops in a way sensitive to boundary symbols (section 4.1). Next we move down to the smaller prosodic unit, the syllable. We place all of those boundaries which mark syllable edges and which were not already inserted at the foot level. At this point we apply the devoicing rules, giving the correct outputs (sections 4.2-4.3). The foot-based boundary symbols do not get in the way of the syllable-based boundary symbols, precisely because all foot edges are also syllable edges. We see this concretely in a form like [?áp?cbən] 'to ebb away' from |áb|cbən|. The boundary symbol between the prefix and the verb corresponds to a foot edge in hierarchical theories. A glottal stop is inserted here, but because all foot edges are also syllable edges, that same boundary symbol also triggers syllable-final devoicing of the $/ \mathrm{b} / \mathrm{at}$ the end of 
the prefix. There are no cases where we see a glottal stop without also seeing devoicing of a preceding voiced obstruent.

Because of these containment relations, a German analysis works as long as we place the rules relating to larger prosodic units like feet before those rules which relate to smaller prosodic units like syllables. This top-down perspective is the exact opposite of the traditional bottom-up approach where we first build smaller units, and then build larger units on top of those. UBT predicts that this should hold in general across languages, something which places strong restrictions on how phonological processes interact. For example, it should be impossible to have a language where a syllable-level process feeds or counterfeeds a foot-level process. In general, phonological processes apply top-down from larger to smaller prosodic units. This prediction is not made by other theories of prosodic representations, and can easily be tested by consulting grammars for a large number of languages to check for counterexamples.

When evaluating this prediction, two important caveats must be kept in mind. Because of the interactions between phonology and syntax, apparent violations of this top-down assumption will surely arise. If the syntax gradually adds to phonological inputs one phase at a time, as I have assumed in this paper, this will give the phonology smaller single-phase units which are then built up into larger multi-phase units. In this way, word-level phonology is able to feed phrase-level phonology. UBT predicts that this is impossible in cases where the syntax is not involved. It will also be the case that some prosodic processes do not require the presence of a boundary in UBT. For example, if stress is seen as a property of feet, a language with consistent initial stress might require a foot at the left edge of every word. But in UBT, it is not necessary to insert a boundary symbol in order to place stress on the leftmost vowel, something which can be done with a simple segmental rule. Taking these caveats into account, a more careful statement of the unique prediction made by UBT is instead: barring cyclicity, if boundary symbols are needed, phonological processes apply top-down from larger to smaller prosodic units.

6. Conclusions. This paper has analyzed the prosodic phonology of German, focusing on glottal stop insertion and devoicing. Although these phenomena are usually described in terms of feet and syllables, I have shown that an analysis is possible in Universal Boundary Theory (UBT), which has no such prosodic units and only a single boundary symbol to represent prosodic edges. UBT allows us to write both processes as applying in an environment which is sensitive to the boundary symbol |, without the complicated disjunctions over environments required in earlier boundary-based approaches such as SPE (Chomsky and Halle 1968). UBT successfully accounts for all aspects of the German data: the exact environment for devoicing, the interactions between syntax and phonology in morphologically complex forms, as well as affix-specific behavior in glottal stop insertion. The UBT analysis is also more than just a restatement of a traditional approach based on a prosodic hierarchy. Because of its limited representational apparatus, UBT is not predictively equivalent to hierarchical approaches, and in fact, the theory predicts a new prosodic universal: phonological processes apply top-down from larger to smaller prosodic units. This is a clear and empirically falsifiable prediction. Future typological work can shed light on the extent to which the prediction holds crosslinguistically, thereby supporting or falsifying Universal Boundary Theory.

\section{References}

Alber, Birgit. 2001. Regional variation and edges: Glottal stop epenthesis and dissimilation in Standard and Southern varieties of German. Zeitschrift Für Sprachwissenschaft 20(1). 3-41. https://doi.org/10.1515/zfsw.2001.20.1.3. 
Andersson, Samuel. 2019. We should set some boundaries: Phonology in Universal Boundary Theory. Invited talk. Workshop on Theoretical Phonology. Montreal.

Andersson, Samuel. 2020. Let me stress how flat phonology is: The segmental feature [stress] in Abkhaz. 44th Penn Linguistics Conference. Philadelphia, PA.

Banovics, Aaron. 2012. Strukturelle und intervenierende Kompensationsstrategien: Ausgewählte Partizipationschancen von sehgeschädigten Personen in Österreich, Eine qualitative Studie Vienna: Universität Wien dissertation.

Biskup, Petr, Michael Putnam \& Laura C. Smith. 2010. German particle and prefix verbs at the syntax-phonology interface. Leuvense Bijdragen 97. 106-135.

Blevins, Juliette. 1995. The syllable in phonological theory. In John Goldsmith (ed.), The handbook of phonological theory. 206-244. Oxford: Blackwell.

Booij, Geert. 1985. Coordination reduction in complex words: A case for prosodic phonology. In Harry van der Hulst \& Norval Smith (eds.), Advances in non-linear phonology. 143160. Dordrecht: Foris.

Brockhaus, Wiebke. 2012. Final devoicing in the phonology of German. Tübingen: Max Niemeyer.

Chomsky, Noam \& Halle, Morris. 1968. The sound pattern of English. New York: Harper \& Row.

Clements, George N. 1985. The geometry of phonological features. Phonology 2(1). 225-252. https://doi.org/10.1017/S0952675700000440.

Faust, Noam \& Ulfsbjorninn, Shanti. 2018. Arabic stress in strict CV, with no moras, no syllables, no feet and no extrametricality. The Linguistic Review 35(4). 561-600.

Féry, Caroline. 1995. Alignment, syllable and metrical structure in German. SfS-Report-02-95. Tübingen.

Féry, Caroline. 2004. Phonologie des Deutschen: Eine optimalitätstheoretische Einführung. Potsdam: Universitätsverlag Potsdam.

Gibbon, Dafydd. 1998. German intonation. In Daniel Hirst \& Algert di Cristo (eds.), Intonation systems: A survey of twenty languages. 78-95. Cambridge: Cambridge University Press.

Goldsmith, John. 1995. The Syllable. In John Goldsmith (ed.), The Handbook of phonological theory. 164-196. Oxford: Blackwell.

Hall, Tracy A. 1992. Syllable structure and syllable-related processes in German. Tübingen: Niemeyer.

Hall, Tracy A. 1999. Phonotactics and prosodic structure of German function words. In Tracy A. Hall \& Ursula Kleinhenz (eds.), Studies on the phonological word. 99-132. Amsterdam/Philadelphia, PA: John Benjamins Publishing.

Hall, Tracy A. 2005. Paradigm Uniformity Effects in German Phonology. Journal of Germanic Linguistics 17(4). 225-264. https://doi.org/10.1017/S1470542705000097.

Halle, Morris \& Jean-Roger Vergnaud. 1987. Stress and the cycle. Linguistic Inquiry 18(1). 4584.

Hayes, Bruce. 1995. Metrical stress theory: Principles and case studies. Chicago, IL: University of Chicago Press.

Heinz, Jeffrey N. 2007. Inductive learning of phonotactic patterns. Los Angeles, CA: University of California dissertation.

Idsardi, William J. 2009. Calculating metrical structure. In Eric Raimy \& Charles E. Cairns (eds.), Contemporary views on architecture and representations in phonology. 191-212. Cambridge, MA: MIT Press. 
Itô, Junko \& Armin Mester. 2003. On the sources of opacity in OT: Coda processes in German. In Caroline Féry \& Ruben van de Vijver (eds.), The syllable in Optimality Theory. 271-303. Cambridge: Cambridge University Press.

Iverson, Gregory K \& Joseph C. Salmons. 2007. Domains and directionality in the evolution of German final fortition. Phonology 24(1). 121-145. https://doi.org/10.1017/S0952675707001133.

Kolek, Vit. Forthc. Options for labelling non-heteronormative people in a German-Czech comparison. In Dennis Scheller-Boltz (ed.), Language policies in the light of antidiscrimination and political correctness: Tendencies and changes in the Slavonic languages. Frankfurt: Peter Lang.

Kloeke, Wus van Lessen. 1982. Deutsche Phonologie und Morphologie: Merkmale und Markiertheit. Tübingen: Max Niemeyer.

Kohler, Klaus J. 1994. Glottal stops and glottalization in German. Phonetica 51(1-3). 38-51. https://doi.org/10.1159/000261957.

Liberman, Mark. 1975. The Intonational System of English. Boston, MA: MIT dissertation.

Mailhot, Frédéric \& Charles Reiss. 2007. Computing long-distance dependencies in vowel harmony. Biolinguistics 1.28-48.

Miller, Taylor. 2019. Navigating the phonology-syntax interface and tri-P mapping. Invited talk. 7th Annual Meeting on Phonology (AMP). Stony Brook, NY.

Nespor, Marina \& Irene Vogel. 1986. Prosodic Phonology. Dordrecht: Foris.

Newell, Heather. 2019. Functional vs lexical structure without the Prosodic Hierarchy. Invited talk. Segmental Processes in Interaction with Prosodic Structure (SPIPS). Troms $\varnothing$.

Nicenboim, Bruno, Timo B. Roettger \& Shravan Vasishth. 2018. Using meta-analysis for evidence synthesis: The case of incomplete neutralization in German. Journal of Phonetics 70. 39-55. https://doi.org/10.1016/j.wocn.2018.06.001.

Reiss, Charles. 2009. Long-distance dependencies and other formal issues in phonology. In Eric Raimy \& Charles E. Cairns (eds.), Contemporary views on architecture and representations in phonology. 247-258. Cambridge, MA: MIT Press.

Samuels, Bridget. 2009. The structure of phonological theory. Boston, MA: Harvard University dissertation.

Samuels, Bridget. 2010. Phonological derivation by phase: Evidence from Basque. University of Pennsylvania Working Papers in Linguistics (PWPL) 16(1). 166-175.

Sande, Hannah, \& Peter Jenks. 2018. Cophonologies by phase. Proceedings of the Northeast Linguistic Society (NELS) 48. 39-52.

Scheer, Tobias. 2008. Why the prosody hierarchy is a diacritic \& why the interface must be direct. In Jutta M. Hartmann, Veronika Hegedüs \& Henk van Riemsdijk (eds.), The sounds of silence: Empty elements in syntax and phonology. 145-192. Amsterdam: North-Holland Elsevier.

Scheer, Tobias \& Péter Szigetvári. 2005. Unified representations for stress and the syllable. Phonology 22(1). 37-75. https://doi.org/10.1017/S0952675705000436.

Seidl, Amanda. 2001. Minimal indirect reference: A theory of the syntax-phonology interface. London: Routledge.

Selkirk, Elisabeth. 1981. On prosodic structure and its relation to syntactic structure. In Thorstein Fretheim (ed.), Nordic Prosody II. 111-140. Trondheim: TAPIR.

Selkirk, Elisabeth. 1984. Phonology and syntax: The relation between sound and structure. Cambridge, MA: MIT Press. 
Steriade, Donca. 1999. Alternatives to syllable-based accounts of consonantal phonotactics. In Osaku Fujimura, Brian D. Joseph \& Bohumil Palek (eds.), Proceedings of the 1998 Linguistics and Phonetics Conference. 205-245. Prague: The Karolinum Press.

Stratton, James. 2018. The use of the generic masculine, the derivational suffix -in and genderfair innovations in unrehearsed spoken dialogue in modern standard German. Interdisciplinary Journal for Germanic Linguistics and Semiotic Analysis 23(1). 1-52.

Szczepaniak, Renata. 2014. Vowel and consonant epentheses in the history of German from the typological perspective of syllable and word languages. In Javier C. Reina \& Renata Szczepaniak (eds.), Syllable and word languages. 160-180. Berlin: de Gruyter.

Vaux, Bert \& Bridget Samuels. 2018. Abstract underlying representations and prosodic structure. In Diane Brentari \& Jackson L. Lee (eds.), Shaping phonology. 146-181. Chicago, IL: The University of Chicago Press.

Vennemann, Theo. 1972. On the theory of syllabic phonology. Linguistische Berichte 18. 1-18. Wagner, Michael. 2002. The role of prosody in laryngeal neutralization. MIT Working Papers in Linguistics 42. 373-392.

Wiese, Richard. 1996. The phonology of German. Oxford: Oxford University Press.

Yu, Si-Taek. 1992. Unterspezifikation in der Phonologie des Deutschen. Tübingen: Niemeyer.

Zinfoun, Gisela. 2018. Die demokratische Pflicht und das Sprachsystem: Erneute Diskussion um einen geschlechtergerechten Sprachgebrauch. Sprachreport 34. 44-56. 